LA-UR - $86-1547$

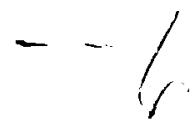

TITLE ANGULAR DEPENDENCE OF MULTILAYER-REFLECTOR DAMAGE THRESHOLDS

$L A-U R--86-1547$

DE86 011265

AUTHOR(S) BRIAN E. NEWNAM, CHM- 6

STEPHEN R. FOLTYN, CHM-5

DENNIS H. GILL, CHM-DO

L. JOHN JOLIN, CHM-5

Submitted to Laser Induced Damage in Optical Materials: 1984,

Proceedings of the 16th Annuai Symposium on Optical Materials for

High-Power Lasers, Boulder, CO, Oct. 15-17, i984.

\title{
DISCLAIMER
}

\begin{abstract}
This report was prepared as an account of work sponsoral hy an agency of the United States Government. Neither the United States Government nor any agency thereof, nor any of their employoen, makes any warranty, express or inuplied, or assumes any legal liability or respunsibillty for the accuracy, completeness, or usefulneas of eny information, apparalus, product, of process dieclosed, or represents that its use would not infringe privately ownod rights. Refer. ence hereln to any apeciflc commercial pruduct, pruceus, or service by trade name, Irademark. manulecturer, or otherwlee does not neceasurily conslitule or imply its endorsement, recom. mendation, or favoring by the United Stutes Government or any agency thereof. The views and opinions of authors expressod herein do not necessarily state or reflect these of the United States Government or eny egoncy theroof.
\end{abstract}

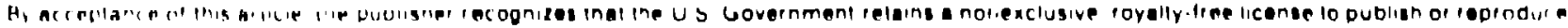

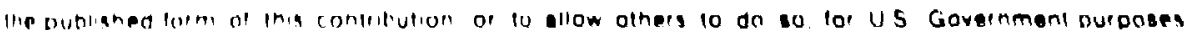

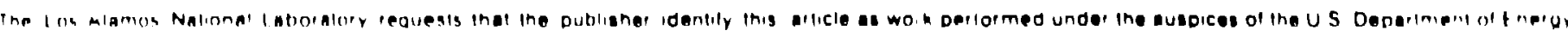

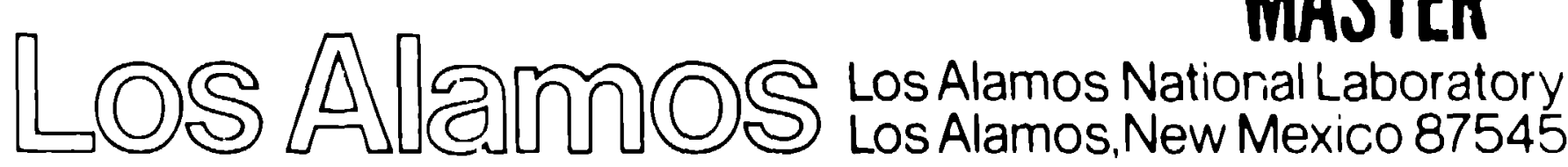


Angular Dependenca of Multilayer-Reflector Damage Thresholds*

Brian E. Newnam, Stephen R. Foltyn, Dennis H. Gill, and L. John Jolin

Los Alamos National Laboratory

Chemistry Division

Los Alamos, New Mexico 87545

The damage resistance of $\mathrm{HfO}_{2} / \mathrm{SiO}_{2}$ multilayer dielectric reflectors was measured as a function of angle of incidence with $351-\mathrm{nm}$ XeF-laser irradiation. The laser produced nominal $10-\mathrm{ns}$ pulses at a repetition rate of 35 pps. A series of reflectors designed for $0^{\circ}, 30^{\circ}, 45^{\circ}, 60^{\circ}, 75^{\circ}$, and $85^{\circ}$ was tested with an S-plane polarized beam. To account for variations in the separate coating depositions, some of the coating designs were testad at two angles of incidence. At iarge angles of incidence, we did nor ubserve the anticipated large increases in damage thresholds predicted theoretically on the basis of spatial dilution $(1 / \cos \emptyset)$ of the intensity at the reflector surface and standing-wave electric fields. For example, the threshold for a reflector designed and tested at $85^{\circ}$ was only a lactor of 2.5 larger than that of normal-incidence reflectors tested at $0^{\circ}$. Several possible mechanisms to explain this discrepancy were considered.

Key words: Coating defects; free-electron lasers; grazing-incidence reflection; hafnium oxide; lacer damage thresholds; multilayer reflectors; multiple-shot laser damage; silicon dioxide; standing-wave electric fields; thin films; ultraviolet reflectors; xenon fluoride lasers.

This work was pertormed under the auspices of the U.S. Department of Energy. 
1. Intraduction

Free-electroil laser (FEL) oscillators, driven by if linee: accelerators, are being designed for high-average power applications in the ultraviolet to the near infrared from 400 to $1000 \mathrm{~nm}$. The pulse format of these oscillators requires mirrors that will not damage or degrade under high peak intensities and high repetition rates ranging from $10^{7}$ to $10^{8} \mathrm{~Hz}$. To function without significant distortior, the resonator mirrors must not be subjected to excossive average-power loading. Thus, very high mirror reflectance is required as well as low optical absorption to minimize the generation of heat and its flow into the water-cooled mirror substrates. Multilayer dielectric (MLD) reflectors are the logical choice for the re-onator mirrors since they have demonstrated the highest reflectance values. For example, reflectances greater than $99.99 \%$ are now obtained for small-diameter, ion-beam deposited reflectors for 633-nm laser gyro cavities. However, resistance to degradation by the total FEL radiation environment remains to be considered.

It is necessary to include FEL physics in establishing the resonator mirror design. Specifically, nigh intracavity intensity is requirau within the magnetic-undulator gain region to obtain efficierit conversion of the electron energy to coherent radiation. With undulator lengths ranging from 1 to 10 meters, the optical beam should have both a siriall waist and low divergence, i.e., a long Rayleigh range. FEL beams have oxhibit desirable characteristic of near-diffraction-limited quality. [1] As a result, very long distances are required betwean the resonator end mirrors to attain an acceptable iritensity loadirig. However, if the mirror separation becomes too long, the ravity becomes less stable and unavoidable mirror fitter can seriously decreaso the overlap of the optical and eloctron beams and thereby reduce the FEL etficiency 
Restriction of the FEL resonator length to minimize the effect of mirror jitter opposes the need for large distances to allow diffaction to dilute the intensity on the mirrors. A solution to this problem is to add a set of slightly curved, intracavity mirrors oriented aı large angles, e.g. $85^{\circ}$, to diverge the optical beam to an acceptable intensity level on the end mirrors. Because the FEL radiation is linearly polarized, these intracavity mirrors are oriented for S-polarized reflection only. Thesretically, use at large angles should result in very high damage resistance and less thermal distortion for a given beam intensity.

Since FEL oscillators are a relatively new development, we have given specia! attention to their mirror neecs in the above discussion. However, bc:h excimer laser and FEL oscillatcr and amplifier optical systems have the common additional requ ireınent for beam-directing mirrors used at non-normal incidence, ano mirror damage data is urgently needed to permit realistic design of these external systems.

For metal mirrors, there have been a few measurements of lasei Jamage resistance and optical absorption at large incidence angles. These demonstrated the theoretically predicted $[1 / \cos \theta]^{2}$ threshold dependence for S-polarization [2,3]. However, data reçarc ing the angular dependence of MLD reflestors is sparse and has been I mitod to incidence angles of $j^{v}$ and $45^{\circ}$.

The present set of experiments was notivated to determine the angular deperidence of multiple-shot ciamage resistance of MLD reflectors for incidence angles from $0^{\circ}$ to $85^{\circ}$ and S-polarized beams. Conducted at the low repeition iate of 35 pps, these test; did not address the issue of average-power Jamage thresholds or Cw thermal distortion of mirrurs which must be evaluatec in future test series with lasnrs operating at high-repotition rates. 
Special considrration was given to the possible role of the standingwave (SW) electric field as a function of angle of incidence because of previous corrolations with damage thresholds. From multiple-shot tests using 10-ns pulses at ultraviolet wavelengths of $248 \mathrm{~nm}$ [4], $308 \mathrm{~nm}$ [5], and $355 \mathrm{~nm}$ [6], we identified the peak SW electric field in the outermost high-index layer as setting the threshold of damage. On this basis, our calculations of the SW fields led us to predict increasingly higher damage thresholds with ang'e of incidence, but only for S-polarized laser beams. The results of these calculations for the specific roflectors tested in the present experiments are shown in Fig. 1 for incidence angles of $0^{\circ}$ and $85^{\circ}$ for both S- and P-polarized beams. The cosine intensity-dilution factor is inierently accounted for in the SW field calculations. The SW fields for angles less than $85^{\circ}$ are intermediate to the curves shown. If optical damage is correlated with the peak value of $\left|E / E_{-}^{+}\right|^{2}$ in the first high-index layer, as would be the case with linear absorption, Fig. 1 indicates that we might expect the damage threshold at $85^{\circ}$ to be a factor of $102 \times$ larger than that at normal incidence.

\section{Test Specimens}

The test specimens were coated by Broomer Labs by electron-beam evapcration with ordinary conditions as used in their commercial production. In addition to the general features listed in Table 1 , particular details of the coating depositions included the following: 300 ${ }^{-} C$ substrate temperature, deposition rate of $5 \mathrm{~min} / \mathrm{QW}, 8 \times 10^{-5}$ Torr background pressure with $\mathrm{O}_{2}$ bleed, and $5 \times 10^{-6}$ Torr initial vacuum. The reflectors were not post baked. For purposes of computing the film thicknesses, Broomer used the refractive indices of 1.51 for $\mathrm{SiO}_{2}$ and 2.08 for $\mathrm{HfO}_{2}$, which are typical values at $351 \mathrm{~nm}$. 
Because the magnitudes of the SW fields can be strongly affected by film thickness errors, wo evaluated the spectral transmittence curves from spectrometer measurements at normal incidence. Comparisons of the Jesign and measured center wavelengths are provided in Table 2. We think that the measured thickness discrepancies should not have influenced the damage thresholds to any great degiee.

Table 1. Test samples

Coating materials: $\quad \mathrm{HfO}_{2}$ and $\mathrm{SiO}_{2}$

Des:gn: $\quad S /(H L)^{11} H^{1}{ }^{2} / A$ for S-polarization

Deposition process: Electron gun

Coating vendor: Broomer Labs

Substrates: $\quad$ Fused silica $(5.1-\mathrm{cm}$ dia.)

BK-7 glass $(6.4 \times 12.7 \mathrm{~cm})$

Table 2. Coating thickness errors

Design Angle Center Wavelength for Nermal'aciderce Deviation ${ }^{b}$ Design (nm) Measured $(n m)^{a}$

\begin{tabular}{llll}
\hline $0^{\circ}$ & 351 & 354 & $+1 \%$ \\
$30^{\circ}$ & 367 & 384 & $+5 \%$ \\
$45^{\circ}$ & 386 & 403 & $+4.5 \%$ \\
$60^{\circ}$ & 407 & 405 & $-0.5 \%$ \\
$75^{\circ}$ & 426 & 420 & $-1.5 \%$ \\
$35^{\circ}$ & 434 & 425 & $-2 \%$ \\
\hline
\end{tabular}


a Wavelength corresponding to the center frequency midway between $1 \%$ transmittance points of the reflection band.

b For $0^{\circ}$ incidence on a reflector designed for $0^{\circ}$, a $3 \%$ thickness error results in $\leq 1 \%$ increase in the SW electric-field peaks. For $85^{\circ}$ incidence (S-polarized light) on a reflector designed for $85^{\circ}$, a $10 \%$ thickness error results in a $25 \%$ increase of the field peak in the uppermost high-index layer and a $20 \%$ increase in the uppermost (HW overcoat) low-index layer.

\section{Laser Darnage Test Conditions}

The laser damage test facility depicted in Fig 2 and our standard multiple-shot measurement procedure; have been described previously. [4,5] One modification, not shown, was inclusion of multilayer polarizers which we aligned very careful'y to obtain a polarization purity of $I_{s} / I_{p}=$ 1000 incident on the samples. In addition, the beam dimensions in the sample plane, which varied with incidence angle, were measured directly with a Reticon silicon-diode linear array. As shown in Table 4, the measured diameters of the near-Gaussian beam did not deviate significantly from the predictions. Naturally, the measured beam sizes were used in calculations of the damage thresholds. Other laser iest parameters are listed in the following table.

Ta.ble 3. Laser test parameters

Wavelength: $\quad 351 \mathrm{~nm}(\mathrm{XeF})$

Polarization: S-plane with purity $I_{S} / I_{P} \geq 1000$

Pulsowidth: $\quad 10$ ns (FWHM)

Spot-size

cliameter $\left(1 / \theta^{2}\right)$ : $\quad 0.4 \mathrm{~mm}$, meaı value normal to beam

$0.4 \mathrm{~mm} / \cos \emptyset$, mean value on sample

Repetition rate: $\quad 3 j \mathrm{pps}$

Shots per site: $\quad 140$ if no damage detected, or $\$ 140$ if damage 
Table 4. Angular dependence of the aser beam diameter (vertical plane) at the reflector surface

\begin{tabular}{cccc}
$\begin{array}{l}\text { Angle of } \\
\text { Incidence }\end{array}$ & $\begin{array}{c}\text { Predicted Diameter } \\
2 w_{0} / \cos \varnothing,(\mathrm{mm})\end{array}$ & $\begin{array}{c}\text { Meiasured Diameter } \\
(\mathrm{mm})\end{array}$ & $\begin{array}{c}\text { Deviation } \\
\text { from 1/cos }\end{array}$ \\
\hline $0^{\circ}$ & 0.128 & 0.128 & --- \\
$30^{\circ}$ & 0.148 & 0.142 & $-4 \%$ \\
$45^{\circ}$ & 0.181 & 0.173 & $-4 \%$ \\
$60^{\circ}$ & 0.256 & 0.235 & $-8 \%$ \\
$75^{\circ}$ & 0.495 & 0.470 & $-5 \%$ \\
$85^{\circ}$ & 1.47 & --- & --- \\
\hline
\end{tabular}

4. Experimental Results

Preliminary to damage tests over the entire range of angles of incidence, the possible threshold variations within a given coating run were determined for the $0^{\circ}$ and $30^{\circ}$ designs. These threshold values, given in Table 5, indicate a range of \pm 10 to $\pm 15 \%$. Also, the 4 to $5 \mathrm{~J} / \mathrm{cm}^{2}$ magnitude is about the same as our previous measurements of other reflectors composed of these same coating materials. Since each angie of incidence required a separate coating d€position, we attempted to account for run-to-run variat.ons by testing some of the reflectors at two angles of incidence. We intended to obtain this two-angle registration for each cnating design, but only $0^{\circ}$ and $30^{\circ}$ designs were so evaluated due to dccreased coating target area available at the larger angles. For these two designs, the variations were within $10 \%$ as shown in Table 6. Predicted differences on the basis of the peak. SW electric fields also were small. 
The results as a function of the full range of incidence angles are listed in Table 7, and the sunporting data from which the threshold values were obtained are presented in the series of Figs. 3. This extensive display of test data is given because of 1) the significance that might be given these results in optical designs of FEL resonators and other beam directing elements, and 2) to allow the reader the opportunity for a thorough examination of these results with the possibility that other interpretations might become evider:.. We note that the available laser energy was insufficient to reach the saturation fluence (damage at 10 out of 10 test sites) for the $85^{\circ}$ case. Figure 4 allows direct comparison of the experimental results for all of the angles of incidence used.

We observed that the damage morphology at high angles of incidence differed from that for near-norialal incidence. At the large angles, the damage sites had an elongated triangular pattern, different from the elliptical beam footpririt, with the long dimension aligned along the direction or the incident beam.

Table 5. Comparison of damage thresholds of $\mathrm{HfO}_{2} \mathrm{SiO}_{2}$ reflectors fabricated in the same coating run

$\begin{array}{lcc}\text { Design- and } & \text { Sample } & \text { Damage Threshold } \\ \text { Test Angle } & \text { Identification } & \mathrm{J} / \mathrm{cm}^{2}\end{array}$

$0^{\circ}$

$0-1$

4.1 
Table 6. Comparison of damage thresholds for $\mathrm{HrO}_{2} / \mathrm{SiO}_{2}$ reflectors tested at two angles of incidence

Sample Design Angle Test Angle Damage Threshold Peak SW

Number $\quad \mathrm{J} / \mathrm{cm}^{2} \quad$ Electric Fieid ${ }^{\mathrm{a}}$

$\begin{array}{ccccc}0-1 & 0^{\circ} & 0^{\circ} & 4.1 & 0.95 \\ & & 30^{\circ} & 4.5 & 0.89 \\ 30-1 & 30^{\circ} & 30^{\circ} & 4.5 & 0.85 \\ & & 45^{\circ} & 4.6 & 0.76\end{array}$

a Calculated in the $\mathrm{HfO}_{2}$ fil:ns (for reflectors centered at $351 \mathrm{~nm}$ ) and normaiized to the S-polarized incident field $\mathrm{E}_{\mathrm{o}}^{+}$.

Table 1. Damage thresholds versus angle of incidence for $\mathrm{HfO}_{2} / \mathrm{SiO}_{2}$ reflectors tested at the design angle

\begin{tabular}{lll}
$\begin{array}{l}\text { Design and } \\
\text { Test Angle }\end{array}$ & $\begin{array}{c}\text { Damage Threshold } \\
\mathrm{J} / \mathrm{cm}^{2}\end{array}$ & $\begin{array}{c}\text { Peak SW } \\
\text { Electric Field }\end{array}$ \\
\hline $0^{\circ}$ & $4.6 \pm 0.5$ & 0.95 \\
$30^{\circ}$ & $4.3 \pm 0.4$ & 0.85 \\
$45^{\circ}$ & 5.2 & 0.72 \\
$60^{\circ}$ & 6.6 & 0.52 \\
$75^{\circ}$ & 6.9 & 0.28 \\
$85^{\circ}$ & $11.5 \pm 0.5$ & 0.094 \\
\hline a Calculated in the $\mathrm{HfO}_{2}$ films (for reflectors centered at $\left.351 \mathrm{~nm}\right)$ \\
and normalized to the S-polarized incident field $\mathrm{E}_{0}^{+}$.
\end{tabular}




\section{Discussion}

It is informacive to compare the angular dependence of the damage thresholds against the predictions of several possible physical models. One obvious model is that the threshold is determined by the laser fluence incident on the outer surface of the reflector. Because the beam footprint becomes elongated as $1 / \cos \varnothing$, the fluence at the surface is diluted by the $1 / \cos \varnothing$ factor. Therefore, in terms of the laser fluence measured normal to the incident beam, which is the value cited when measuring damage thresholds, this model would predict that the threshold should increase as $1 / \cos \emptyset$. The second and third models predict that damage resistance is inversely proportional to some power of the peak SW electric iields in the high-index coating. In one case, the fields were computed for the case of a $100 \%$ S-plane polarized incident beam. In the other, the fields were computed as if there were a $100 \%$ conversion of the beam to P-polarization.

In Fig. 5, the angular dependence of the measured damage thresholds. normalized to the average result for $0^{\circ}$ incidence, is compared to the predictions of the three modeis considered. Clearly, at large angles the measured damage thresholds fall far below the model predictions for both the $1 / \cos \varnothing$ dilution and the S-polarized peak field-squared which assumes linear absorption. For $85^{\circ}$ incidence, for example, the damage threshold was only 2.5 times larger than at normal incidence. Howover, the P-polarized peak-field-squared model underestimated the thresholds. It is worth citing a similar result obtained at the U. K. Rutherford Appleton Laboratories for reflectors designed for S-polarized laser radiation at 248 $\mathrm{nm}$ using $\mathrm{ThF}_{4}$ /cryolite films [7]. In that case, the single-shot (15-20 ns pulses) threshold of $\sim 15 \mathrm{~J} / \mathrm{i}$, ? 2 at $86^{\circ}$ exceeded that for $0^{\circ}$ incidence, $\sim 3$ $\mathrm{J} / \mathrm{cm}^{2}$, by only a factor oi five. 
Unforiunately, we have insufficient data by which th uniquely determine the cause of the unexpectedly low damage thresholds at large angles of incidence. We have, however, speculated on a number of possible mechanisms. We list the most plausible ones for further consideration:

1. Larger surface areas exposed at large angles result in more coating defects being irradiated, thereby increasing the probability of damage.

2. Reflectors designed for large angles of incidence are composed of thicker films which have lower thresholds (more defects).

3. Nonuniform SW electric fields may occur near coating defects, and the near-field diffraction field maxima directly behind opaque coating defects could be very large.

4. Scattered light trapped within the layers by total internal reflection could either incraase the effective film absorption or be channeled to absorbing coating defects. See Fig. 6.

5. Pinholes in the coatings could act like light tunnels. At large angles, incident radiation could be funneled into the interior more or less independent of the angle of incidence.

6. The angular dependence of damage may be only a measure of film defects at the air-film interface. Protruding defects could interact with the $S W$ electric-field maxima in air, $2 E_{\mathrm{O}}$, which are much larger than those in the interior of the multilayer [8]. With increasing angle, the location of the SW peaks moves away from the air-film interface. 
7. The polarization purity of the incident beam $\left(I_{S} / I_{p} \geq 1000\right)$ might have been Jegraded upon scattering within the multilayers or rotated by coating birefringence. Depolarization of scattered light from multilayeis has be日n observed previousiy [9]. (Almost total depolarization $\left[I_{S} / I_{P}=1\right]$ of the entire beam would have b: en necessary to produce the observed lower thresholds.)

8. The coating depositions for the $60^{\circ}-, 75^{\circ}-$, and $85^{\circ}$-reflectors may have produced more absorbing films.

Although we have no supporting evidence to absolutely distinguish between the above speculations, we suspect that items 1 to 5 are more plausible than items 6 to 8 . Further clarification will require auxiliary tests, e. g., calorimetric measurements of absorption which could detect any unexpected (spatially averaged) increases in reflactor absorption at large angles due, for example, to trapped scattered light. If film scatter is responsible for restricted thresholds at large angles, reflectors produced by coating deposition processes that produce films with less scatter should be tested. Thase processes include if spuitering, ion-beam sputtering, and ion-assisted electron-beam deposition. According to S. LU, however, the measuieci absorption of ion-beam-deposited reflectors for an S-polarized $633 \mathrm{~nm}$ bearn was the same at $0^{\circ}$ and $45^{\circ}[10]$.

The experimental data as shown In Figs. 4 and 5 exhibited a second feature that is not understond. For angles of incidence from $0^{\circ}$ to $45^{\circ}$, the slopes (\% damage/energy fluence) increased as expected, since the spot area was increasing and more defects were irradiatod. As first revealed by Foltyn [11], Increasea irradiation area should result in steeper slopes, but the threshold ( $0 / 10$ sites damage) should remain essentially the same. 
However, for incidence angles from $45^{\circ}$ to $85^{\circ}$, the present experimental data produced slopes which declined with increasing angle. There is an opportunity for some clever detective work to explain this.

\section{Conclusions}

The damage resistance of $\mathrm{HfO}_{2} / \mathrm{SiO}_{2}$ multilayer dielectric reflectors was measured as a function of angle of incidence from $0^{\circ}$ to $85^{\circ}$ using S-polarized, 10-ns, 351-nm XeF-laser pulses at 35 pps. At large angles

of incidence, we did not observe the anticipated large increases in damage threshold predicted theoretically on the basis of either spatial dilution $(1 / \cos \theta)$ of the intensity at the reflector surface or SW electric fields. For example, the threshold for a reflector designed and tested at $85^{\circ}$ was only a factor of 2.5 larger than that of normal-incidence reflectors tested at $0^{\circ}$. The absence of correlation with the peak SW fields is contrary to frevious experience with non-quarter-wave reflector designs at UV wavelengths. We have considered several possible inechanisms to explain this discrepancy, but further testing is necessary to prove whether any of these are responsible.

\section{References}

[1] Newnam, B. E. Capabilities of broadly tunable free-electron lasers. New Lasers for Analyticaland Industrial Chemistry. Proc. SPIE 461; $184.90-97$.

[2] Goldstein, 1.; Bua, D.; Horrigan, F. A. Pulsed laser damage to uncoated metalliz reflectors. Nat. Bur. Stand. (U. S.) Spgc. Publ. 435; 1976. 41-48.

[3] Figueira, J. F.; Thomas, S. J.; Harrison, R. F. Damage thresholds to metal mirrors by short-pulse $\mathrm{CO}_{2}$ laser radiation. Nat. Bur. Stand.

(U S) Spec. Publ. 638; 1983. 229-238. 
[4] Newnam, B. E.; Foltyn, S. R.; Jolin, L. J.; Carniglia, C. K. Multiple-shot ultraviolet laser damage resistance of nonquarterwave reflector designs for $248 \mathrm{~nm}$. Nat. Bur. Stand. (U. S.) Spec. Publ. 638; 1983. 363-371.

[5] Foltyn, S. R.; Jolin, L. J.; Newnam, B. E. Progress in ultraviolet damage testing at Los Alamos. Nat. Bur. Stand. (U. S.) Spec. Publ. 669; 1984. 266-273.

[6] Carniglia, C. K.; Hart, T. T.; Rainer, F.; Staggs, M. C. Recent damage results on high reflector coatings at $355 \mathrm{~nm}$. Nat. Bur. Stand. (U S.) Spec. Publ. 688; 1985. 347-353.

[7] M. Lunt, Technical Optics, Ltd., private communication on damage test results of their reflectors as reported to him by F. O'Neill of Rutherford Appleton Laboratory, United Kingdom.

[8] P. A. Temple, Naval Weapons Laboratory, private communication; also, Total internal reflection microscopy: a surface inspection technique. Appl. Opt. 20, 2656 (1981).

[9] J. O. Porteus, Naval Weapons Laboratory, private communication.

[10] S. Lu, Litton Industries, private communication.

[11] Foltyn, S. R. Spotsize effects in laser damage testing. Nat. Bur. Stand. (U.S.) Spec. Putl. 669; 1984. 368-379. 


\section{Figure Captions}

Figure 1. Standir.g-wave electric-field distributions in $\mathrm{HfO}_{2} / \mathrm{SiO}_{2}$ reflectors designed for $0^{\circ}$ - and $85^{\circ}$-incidence. Fields are plotted normaized to $E_{0}^{+}$, the incident electric field in air. At large angles such as $85^{\circ}$, the fields for S-polarized radiation are much lower than for normal incidence; modest advantage is attained with P-polarization. For angles smaller than $85^{\circ}$. intermediate field distributions are calculated.

Figure 2. Schematic of the Los Alamos excimer-laser, multiple-shot, laser-damage test facility.

Figures 3a-f. Multiple-shot laser damage test results for $351-\mathrm{nm}$ $\mathrm{HfO}_{2} / \mathrm{SiO}_{2}$ multilayer reflectors as a function of angle of incidence with S-polarization.

Figure 4. Angle dependence of multiple-shot damage thresholds sı Immarized from test results given in Figs. 3.

Figgure 5. Measured damage thresholds normalized to the average result for norr. al incidence are compared to the predictions of three models: 1) $1 / \cos \oslash$ dilution of the fluence at the ruflector surface, 2) inverse of the normalized peak electric-fieldsquared in the top $\mathrm{HfO}_{2}$ layer for S-polarized light, and 3) for P-polarization. The measured damage thresholds fall far below the model predictions.

Figure 6. One physical model that may explain the anomalously low damage thresholds at large incidence angles: Scattered light, trapped in the layers by total internal reflection, could either sufficiently ralse the effective absorption or channel radiation to absorbing defects. 


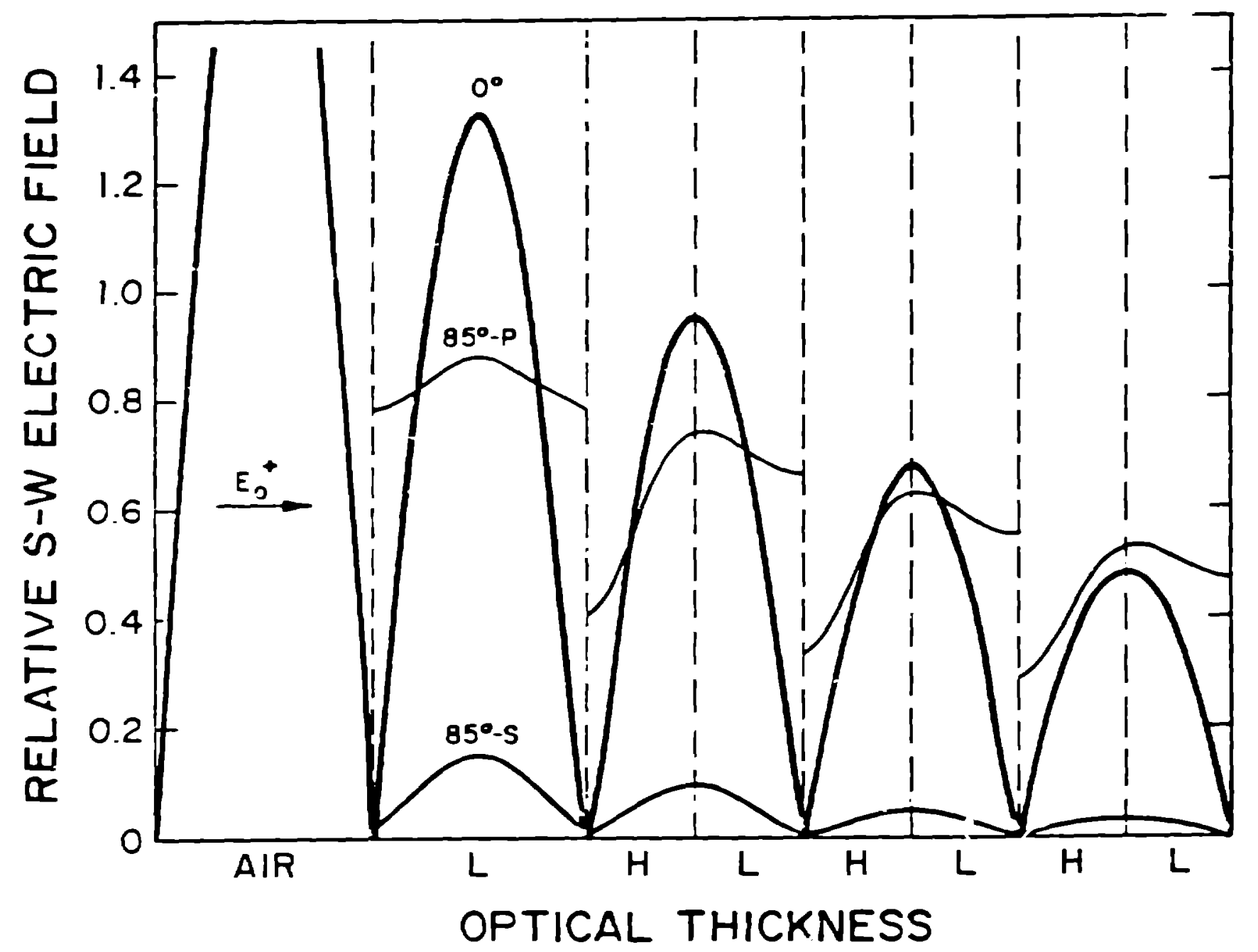

CHM-VG - 7140 


\section{MULTIPLE-SHOT LASER DAMAGE TEST FACILITY}

- real time video monitoring

- VIDEO RECORDING
- COMPUTER ASSISTED TESTING

- COLOR MICROSCOPY

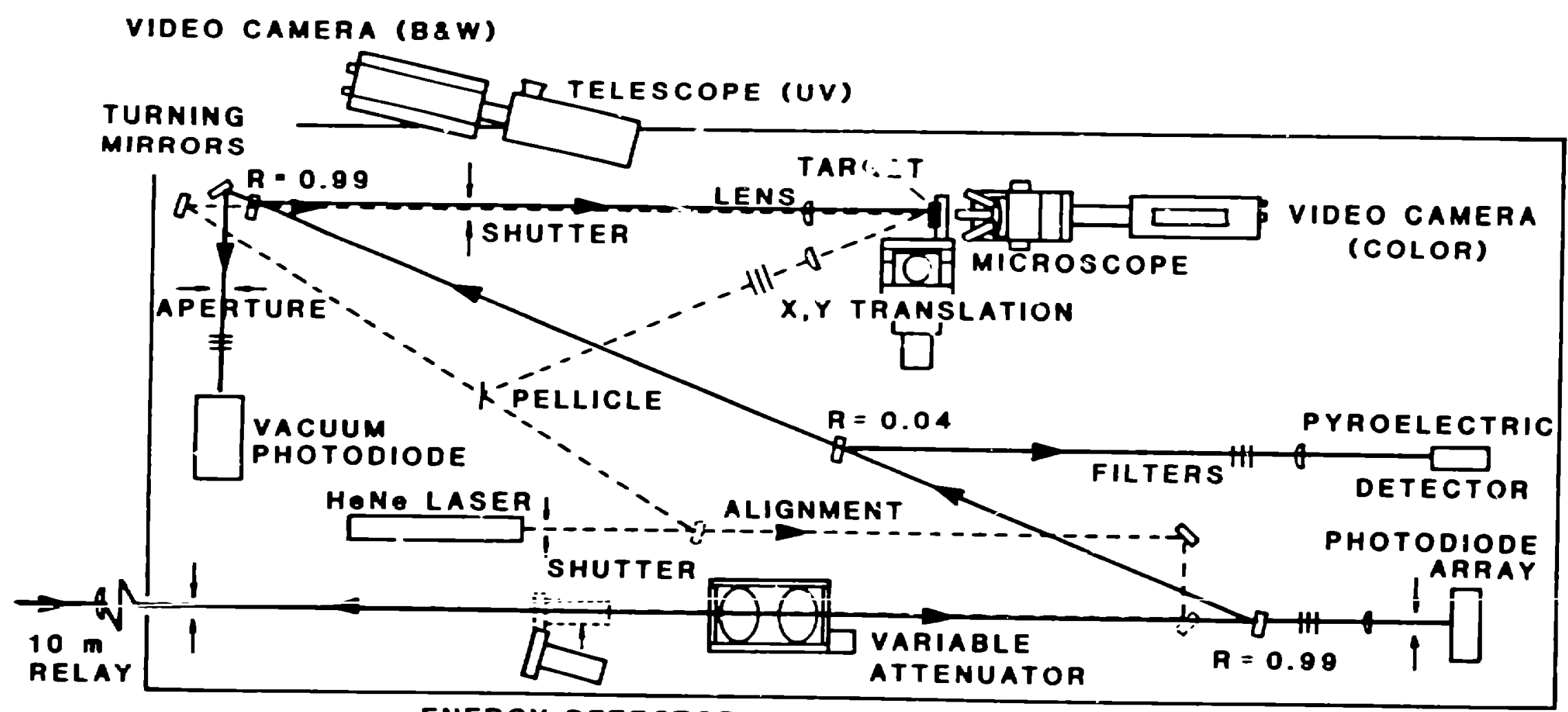

ENERGY DETECTOR 


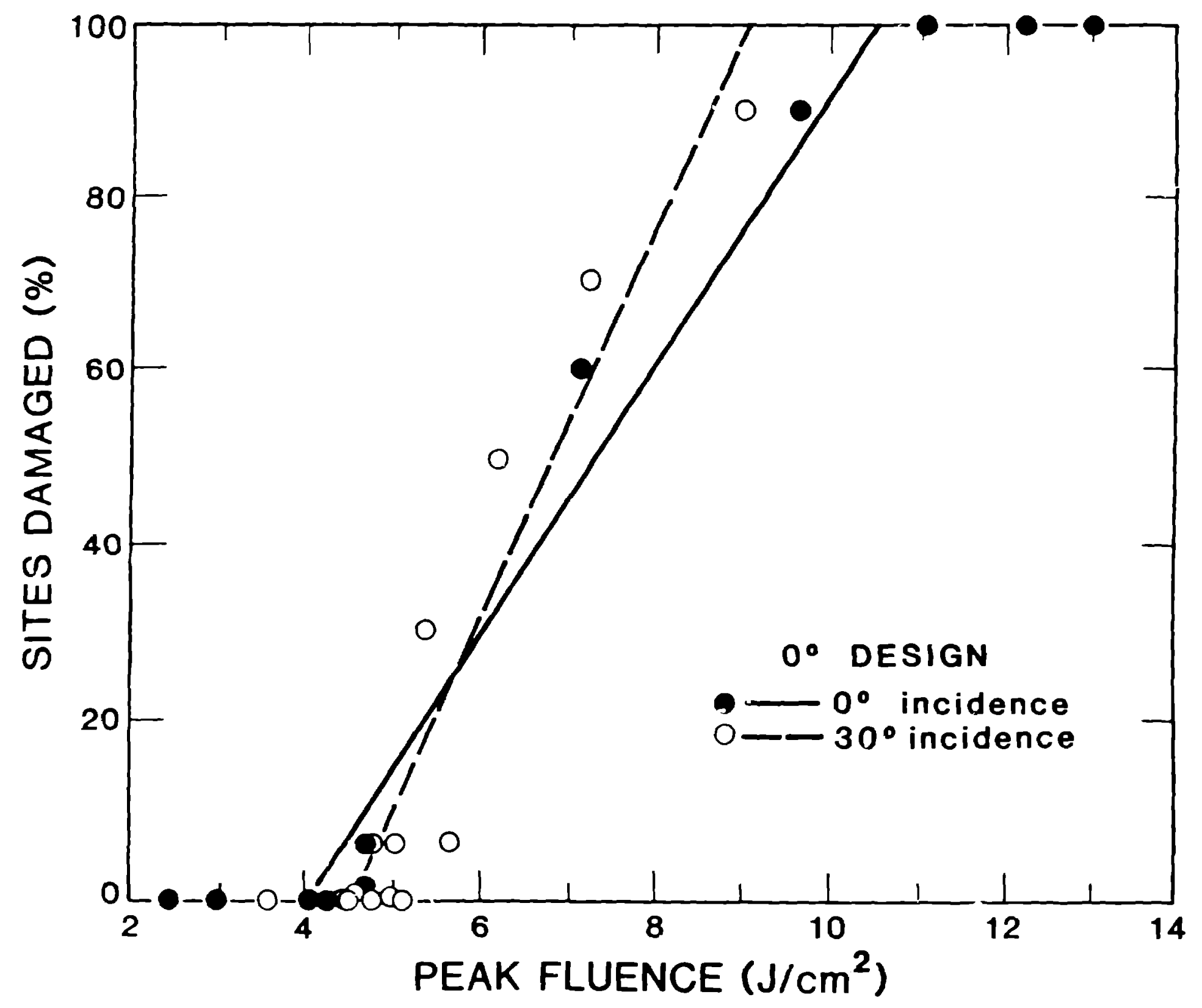

$C H M-V G-10,502$ 


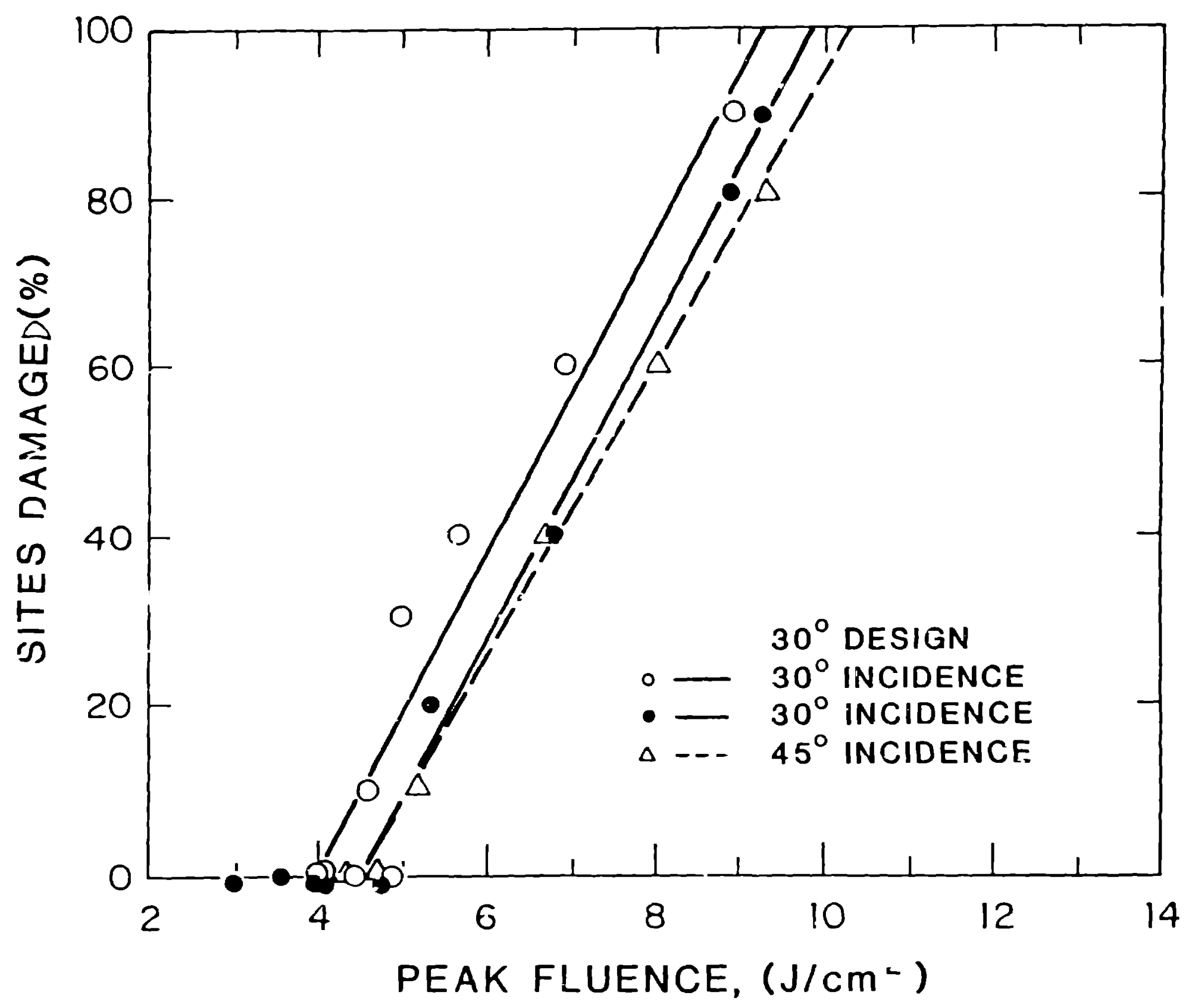

$C H M-V G-10,514$ 


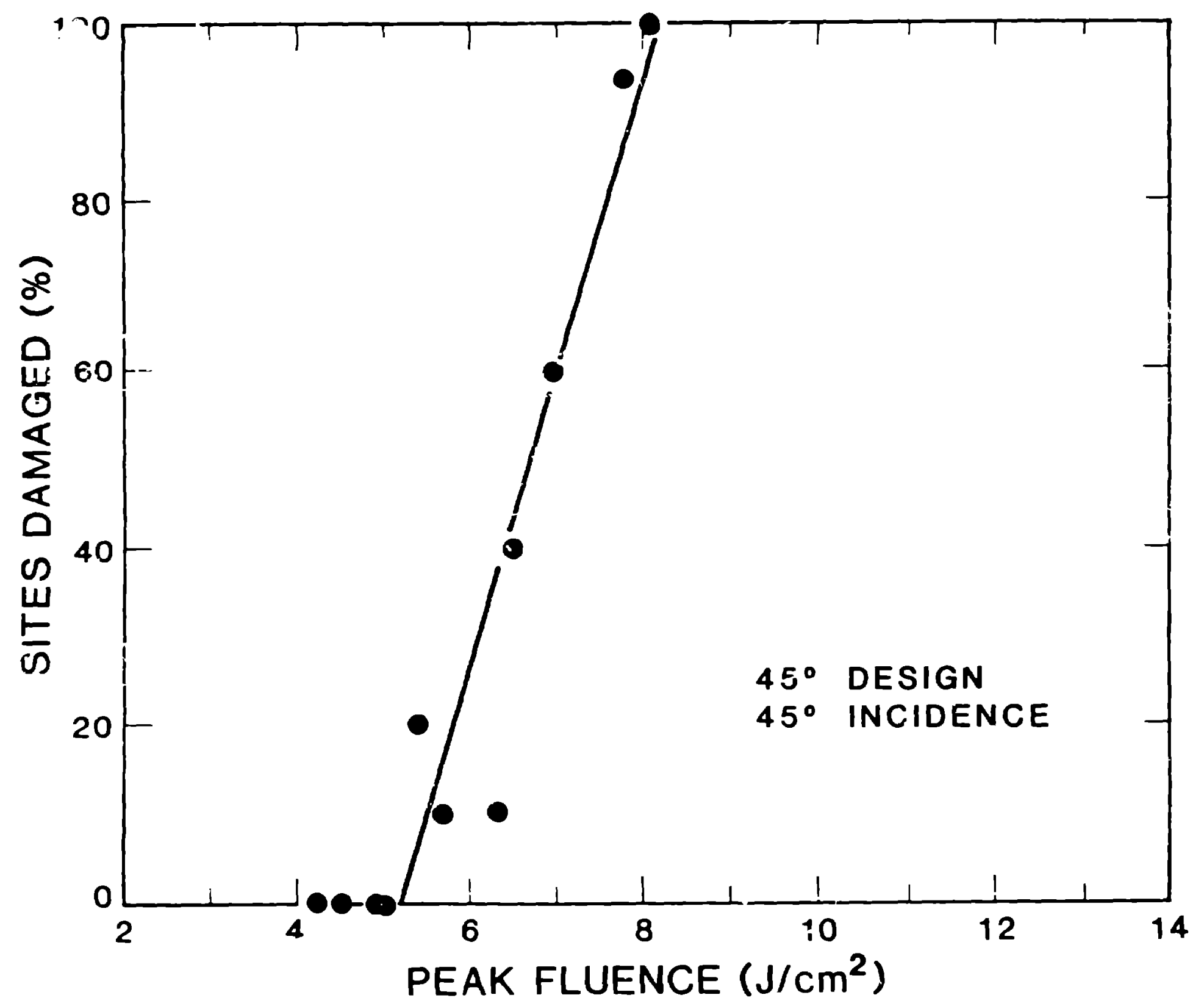

CHM-VG-10,497 


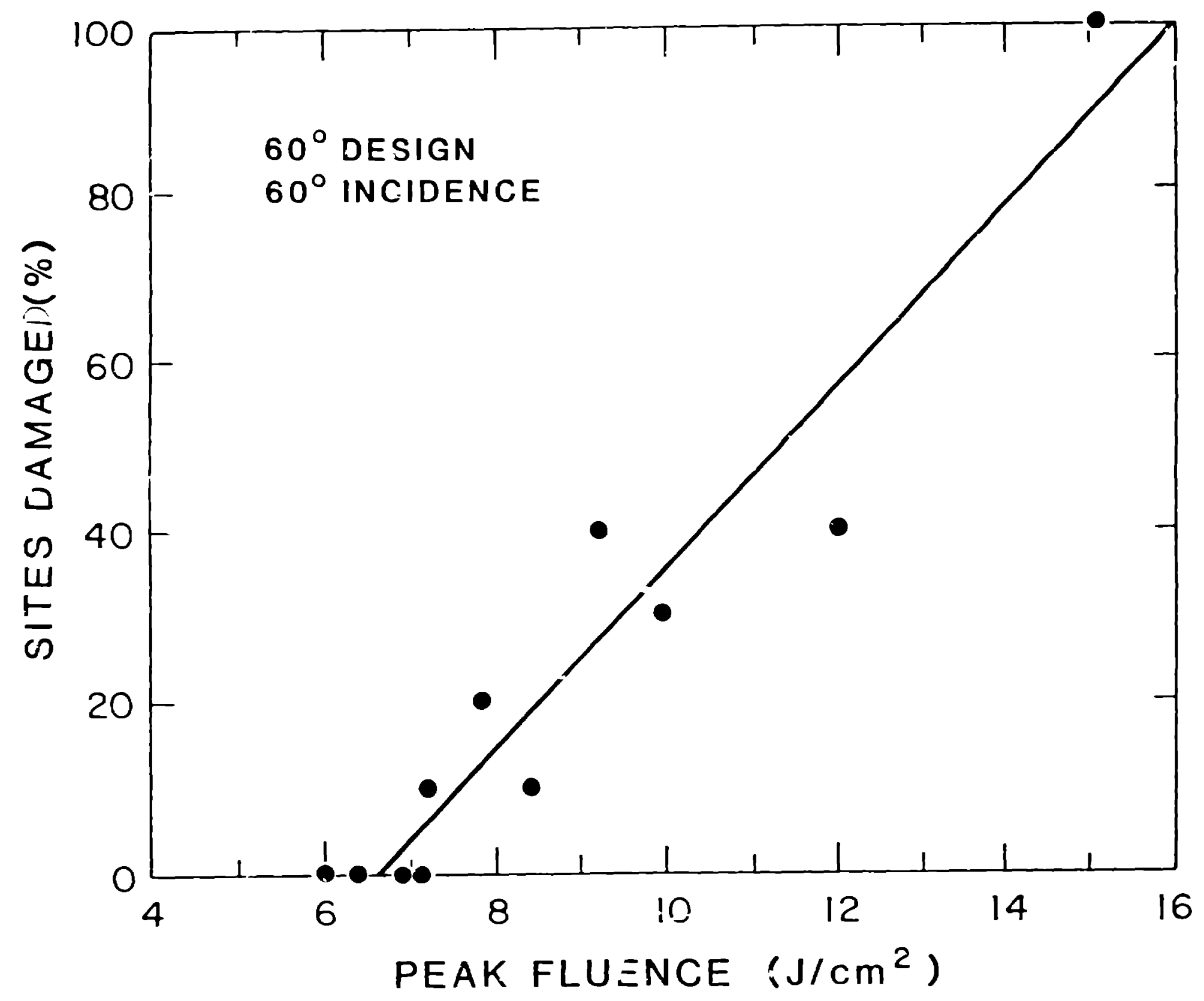

CHM-VG-10.513 


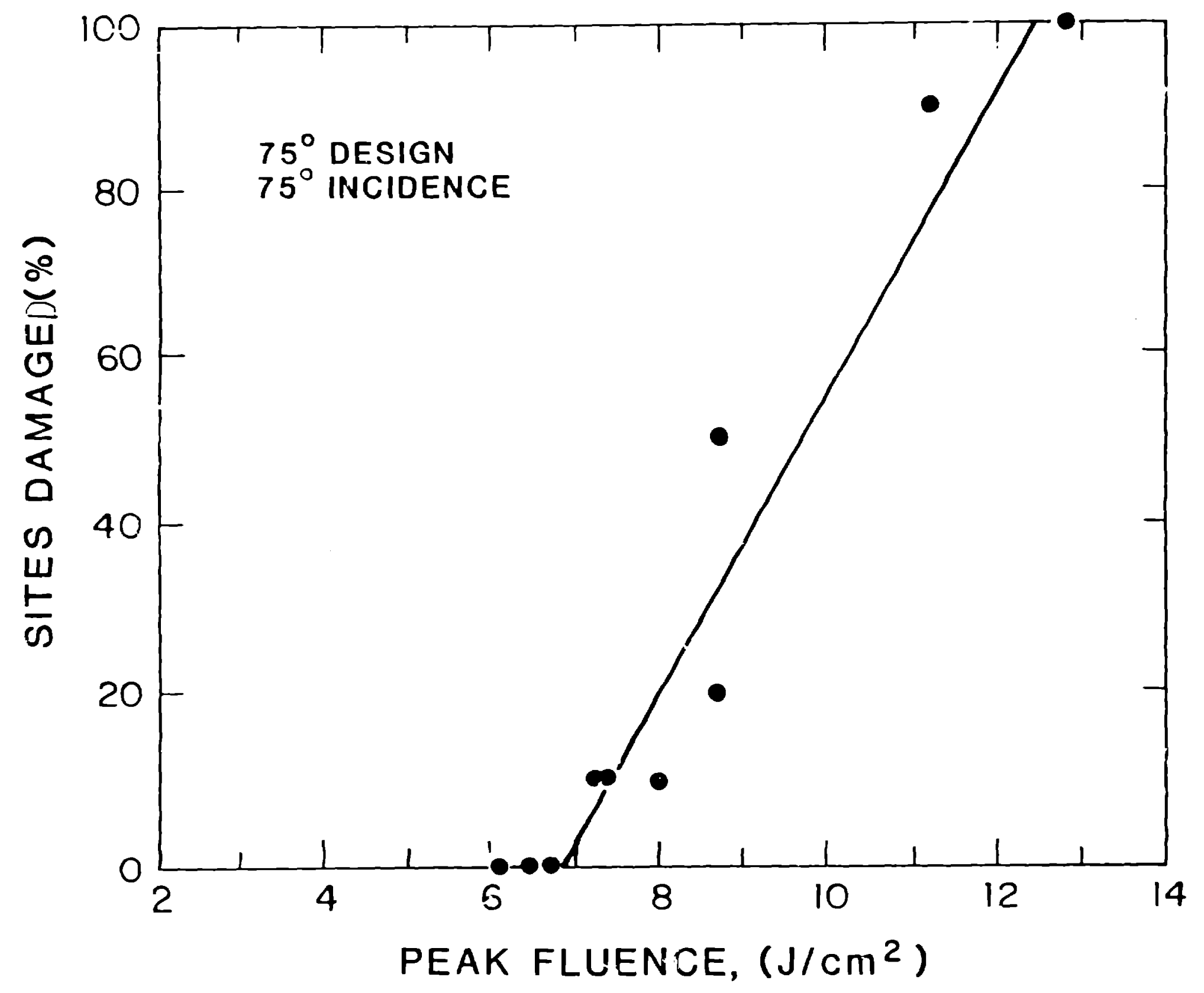

CHM-VG-10.515 


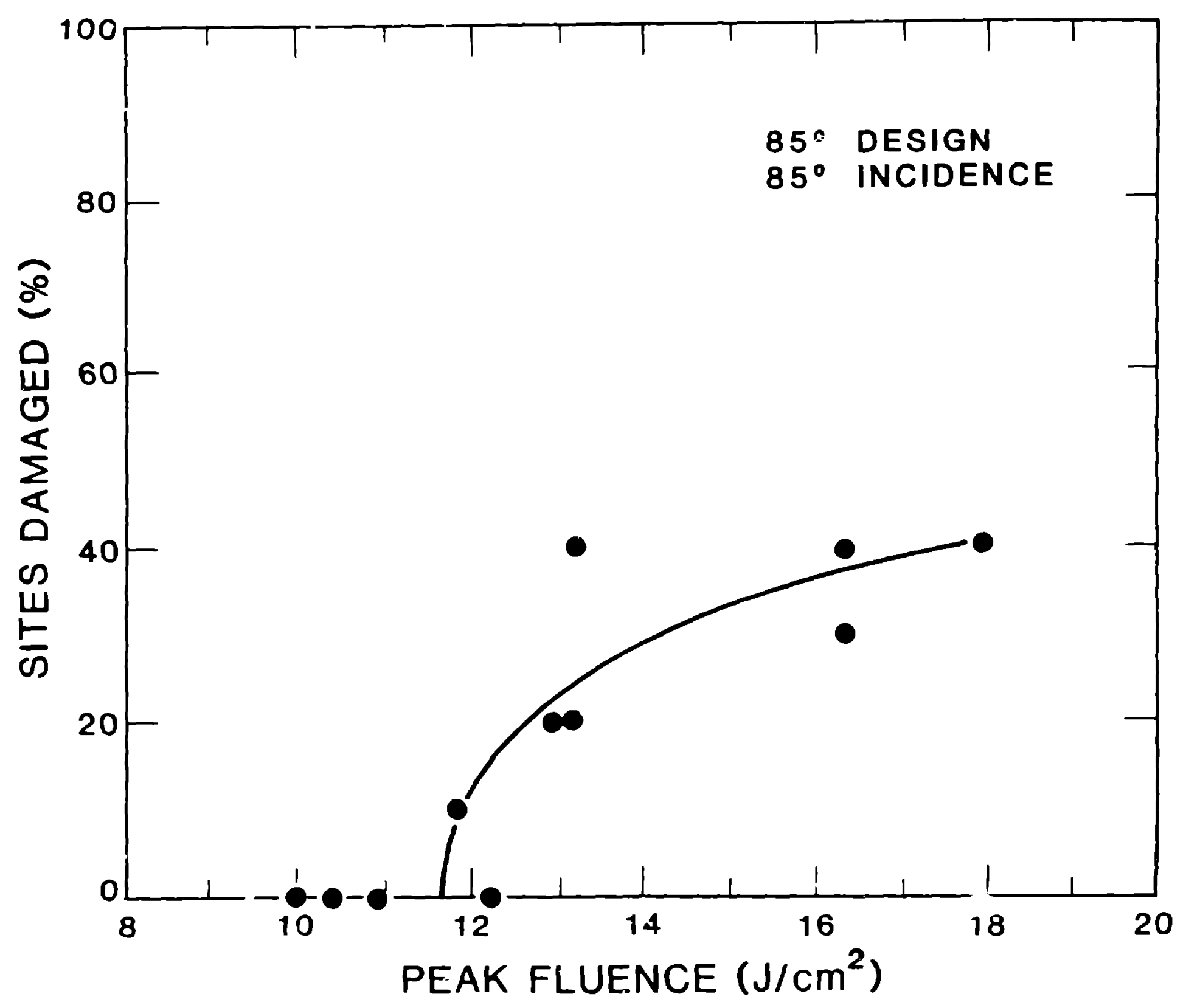

CHM-VG-10,498 


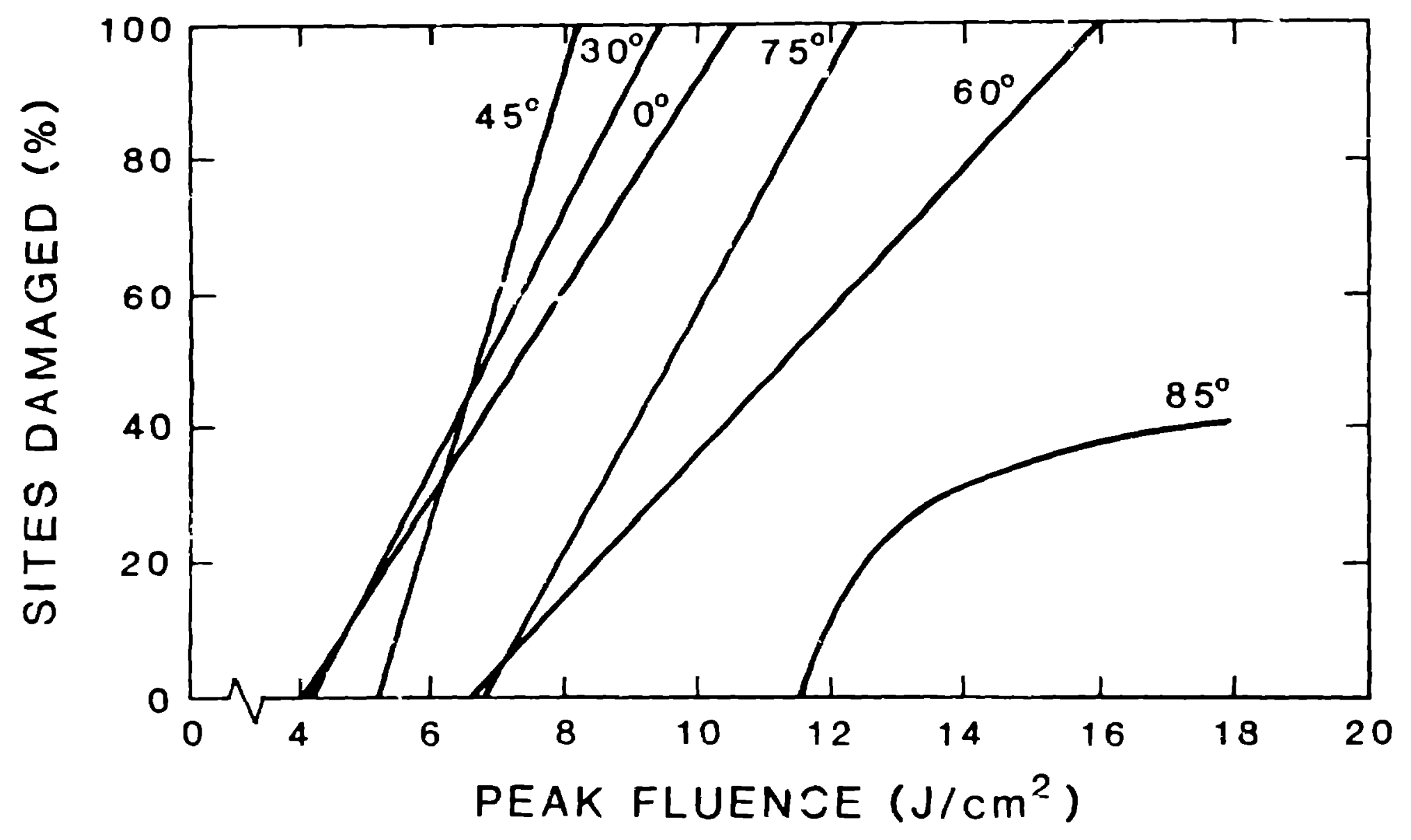

$C H M-V G-10.494$ 


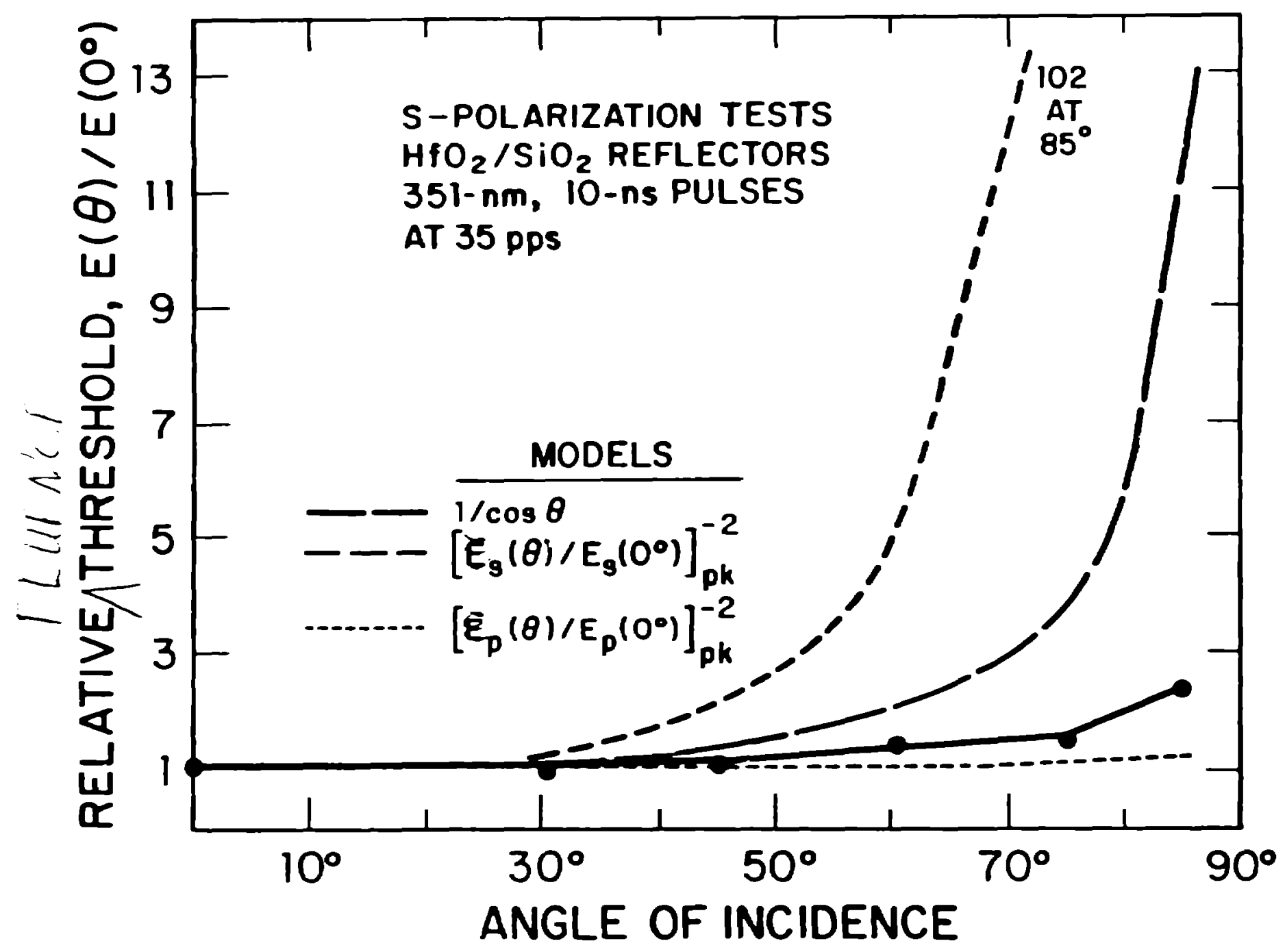




\section{TRAPPED SCATTERED LIGHT INCREASES ABSORPTION}

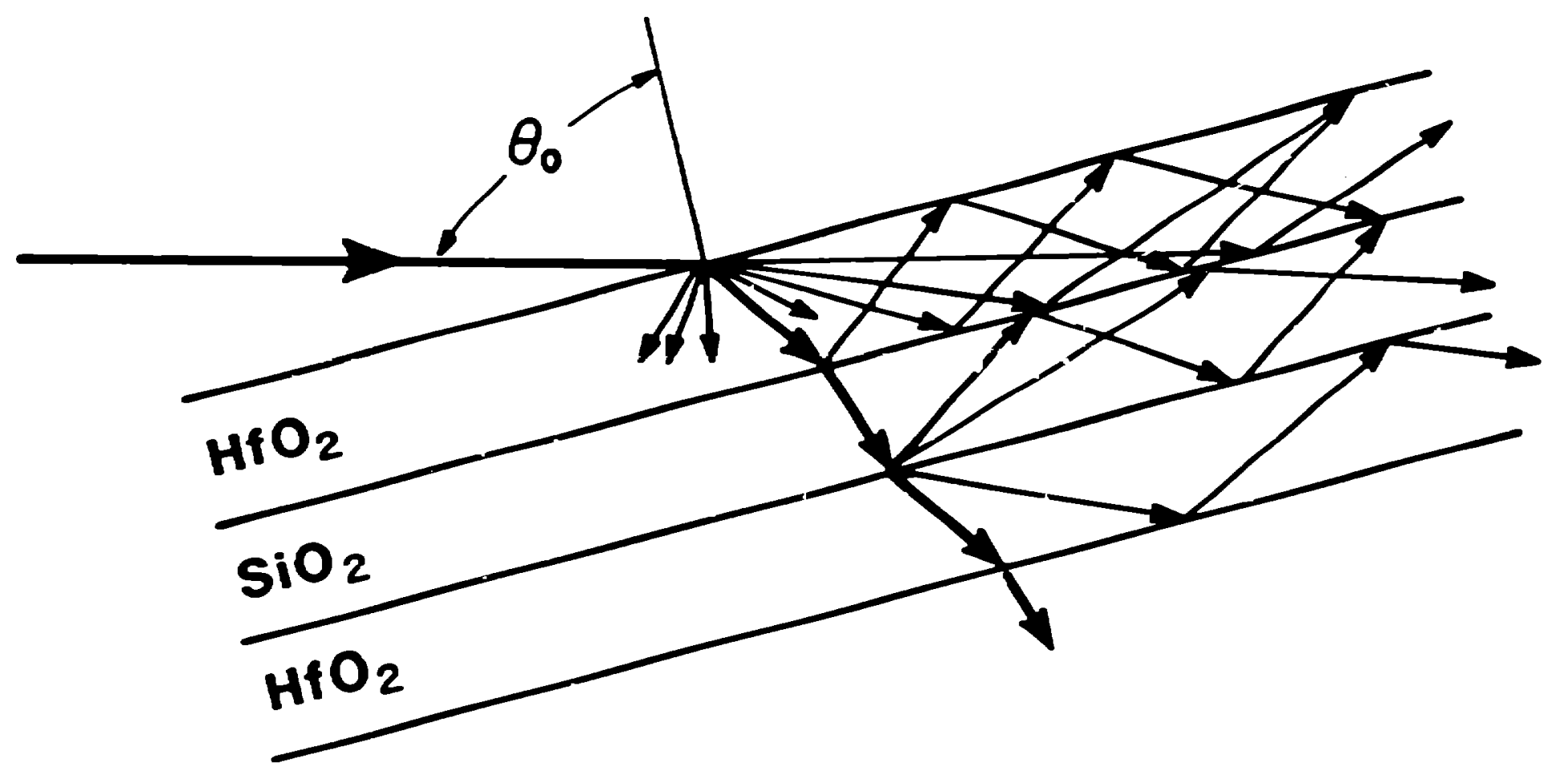

